\title{
Effects of Cell Cycle Regulators on the Cell Cycle Synchronization of Porcine induced Pluripotent Stem Cells
}

\author{
Dae-Jin Kwon ${ }^{1,2^{*}}$, In-Sul Hwang ${ }^{1 *}$, Tae-Uk Kwak ${ }^{1}$, Hyeon Yang $^{1}$, Mi-Ryung Park ${ }^{1}$, Sun-A Ock ${ }^{1}$, \\ Keon Bong $\mathrm{Oh}^{1}{ }^{1}$, Jae-Seok Woo ${ }^{1}$, Gi-Sun $\mathrm{Im}^{1}{ }^{\text {and }}{ }^{\dagger}$ Seongsoo Hwang ${ }^{1}$ \\ ${ }^{1}$ Animal Biotechnology Division, National Institute of Animal Science, RDA, Wanju 55365, Korea \\ ${ }^{2}$ International Agricultural Development and Cooperation Center, Chonbuk National University, Jeonju 54896, Korea
}

\begin{abstract}
Unlike mouse results, cloning efficiency of nuclear transfer from porcine induced pluripotent stem cells (piP$\mathrm{SCs}$ ) is very low. The present study was performed to investigate the effect of cell cycle inhibitors on the cell cycle synchronization of piPSCs. piPSCs were generated using combination of six human transcriptional factors under stem cell culture condition. To examine the efficiency of cell cycle synchronization, piPSCs were cultured on a matrigel coated plate with stem cell media and they were treated with staurosporine (STA, $20 \mathrm{nM}$ ), daidzein (DAI, $100 \mu \mathrm{M}$ ), roscovitine (ROSC, $10 \mu \mathrm{M})$, or olomoucine (OLO, $200 \mu \mathrm{M}$ ) for $12 \mathrm{~h}$. Flow Cytometry (FACs) data showed that piPSCs in control were in G1 $(37.5 \pm 0.2 \%), \mathrm{S}$ $(34.0 \pm 0.6 \%)$ and $\mathrm{G} 2 / \mathrm{M}(28.5 \pm 0.4 \%)$. The proportion of cells at G1 in DAI group was significantly higher than that in control, while STA, ROSC and OLO treatments could not block the cell cycle of piPSCs. Both of viability and apoptosis were affected by STA and ROSC treatment, but there were no significantly differences between control and DAI groups. Real-Time qPCR and FACs results revealed that DAI treatment did not affect the expression of pluripotent gene, Oct4. In case of OLO, it did not affect both of viability and apoptosis, but Oct4 expression was significantly decreased. Our results suggest that DAI could be used for synchronizing piPSCs at G1 stage and has any deleterious effect on survival and pluripotency sustaining of piPSCs.
\end{abstract}

Key words : Cell cycle synchronization, Porcine induced pluripotent stem cells (piPSCs), Self-renewal, Pluripotency

\section{INTRODUCTION}

Generally, nuclear transfer (NT) is referred to as the best tool for the generation of transgenic animals with genetically modified somatic cells. However, this technique has some disadvantages in its low efficiency and the development of abnormal clones. In addition, limited proliferative capacity of genetically modified somatic cells may be one of obstacles to be overcome for generation of transgenic pigs with high efficiency (Hwang et al., 2013). Pluripotent stem cells may be alternative cell sources for creating transgenic animals, because they can be accessed more easily the homologous recombination than somatic cells, as well as they can be cloned more efficiently than any other cell types as reported in mouse (Hochedlinger and Jaenisch, 2006).

Unlike mouse results, cloning efficiency of nuclear transfer from porcine induced pluripotent stem cells (piP-

\footnotetext{
Manuscript received February 12, 2017, Received in revised form February 15, 2017, Accepted February 20, 2017

${ }^{\dagger}$ Corresponding Author : Seongsoo Hwang, Ph.D., Animal Biotechnology Division, NIAS, RDA, 1500, Kongjwipatjwi-ro, Wanju, Jeonbuk 55365, Republic of Korea. Tel: +82-63-238-7253; Fax: +82-63-238-7297, E-mail: hwangss@korea.kr

* Dae-Jin Kwon and In-Sul Hwang have contributed equally to this work.
}

This is an Open Access article distributed under the terms of the Creative Commons Attribution Non-Commercial License (http:// creativecommons.org/licenses/by-nc/3.0) which permits unrestricted non-commercial use, distribution, and reproduction in any medium, provided the original work is properly cited. 
SCs) is very low (Fan et al., 2013, Yuan et al., 2014). One of the reasons related this problem may be associated with a cell cycle coordination of donor nucleus and recipient cytoplast (Kim et al., 2002; Kwon et al., 2008). Although an optimal coordination between donor nuclei and recipient cytoplasts is still controversial, the diploid donor nucleus arrested at the G0/G1 phase is considered the best cell cycle stage for the maintenance of normal ploidy in the reconstructed embryo when using metaphase II (MII) stage oocyte as a recipient cytoplast (Campbell et al., 1996). However, a cell cycle characteristic of piPSCs is very similar to human embryonic stem (ES) cells which have an abbreviated cell cycle of 16-18 $\mathrm{h}$ with a very short G1 phase (2-3 h) (Becker et al., 2006; Hanna et al., 2010; Ghule et al., 2011; Kwon et al., 2013). Therefore the piPSCs need to be synchronized at G1 phase before using them as a nuclear donor reconstructed with MII recipient oocyte.

The present study was performed to investigate the effect of cell cycle inhibitors on the cell cycle synchronization of piPSCs generated using combination of six human transcriptional factors. To synchronize piPSCs at G1 phase, cyclin-dependent kinase (CDK) inhibitors; daidzein (DAI), roscovitine (ROSC) and olomoucine (OLO) and a nonspecific inhibitor of PKC and of CDK1; staurosporine (STA), which chemicals are related with cell cycle regulation, were tested and the effects of these chemicals on cell cycle distribution, viability, apoptosis and Oct4 expression of piPSCs were examined.

\section{MATERIALS AND METHODS}

\section{Porcine induced pluripotent stem cells}

Porcine ear fibroblasts (PEFs) were derived from a 10day-old miniature pigs. Lentiviral transduction was performed using the viPS Vector Kit (Thermo Fisher Scientific) following the manufacturer's instructions. The PEFs were then transduced with lentiviral vectors encoding six human transcription factors (OCT4, NANOG, SOX2, C$M Y C, K L F 4$, and LIN28) as previously described. Established piPSCs were cultured on mitomycin $\mathrm{C}$ inactivated mouse embryonic fibroblasts (MEF) feeder with stem cell medium (DMEM/F12 culture medium supplemented with $10 \%$ Knockout serum replacement (KSR; Invitrogen), 10\% FBS (Invitrogen), 50 units $/ \mathrm{mL}$ penicillin (GIBCO), 50 $\mu \mathrm{g} / \mathrm{mL}$ streptomycin (GIBCO), $2 \mathrm{mM}$ L-glutamine (GIB$\mathrm{CO}$ ), $0.1 \mathrm{mM}$ nonessential amino acids (NEAAs, GIBCO), $1 \mu \mathrm{M} \beta$-mercaptoethanol and $20 \mathrm{ng} / \mathrm{mL}$ leukemia inhibitory factor (LIF; Sigma). Colonies were passaged manually into $35 \mathrm{~mm}$ MEF culture dishes with daily exchange of fresh stem cell medium and maintained by manual passage every 4-5 days. In vitro differentiation was determined by embryoid body (EB) formation. EBs were produced using the Aggrewell plate (Stemcell Technologies) following the manufacturer's instructions. The aggregated cells were then transferred to a Petri-dish (BD Falcon) suspension culture in stem cell medium without LIF and the medium was changed every other day for 10 days.

\section{Cell cycle control}

To examine the efficiency of cell cycle synchronization, piPSC colonies were dissociated using trypsin-EDTA (GIB$\mathrm{CO})$ and cultured on a matrigel coated plate with stem cell media. Two days later, they were treated with staurosporine (STA, $20 \mathrm{nM}$ ), daidzein (DAI, $100 \mu \mathrm{M}$ ), roscovitine (ROSC, $10 \mu \mathrm{M}$ ) or olomoucine (OLO, $200 \mu \mathrm{M}$ ) for $12 \mathrm{~h}$, respectively. piPSC of each group was harvested using trypsin-EDTA and subjected for analysis of cell cycle, apoptosis and gene expression.

\section{Immunocytochemistry}

Alkaline phosphatase (AP) staining was performed using the Vector Red Alkaline Phosphatase Substrate Kit I (VECTOR Laboratories) according to the manufacturer's protocol. For immunocytochemistry, porcine iPSCs were fixed and blocked using the Image-iT ${ }^{\circledR}$ FixationPermeabili- 
zation Kit (Molecular probe) according to the manufacturer's protocol. The cells were then incubated with primary antibodies diluted in the blocking buffer for $1 \mathrm{~h}$ at RT. Primary antibodies, Oct4 (1:100; Santa Cruz) and Nanog (1:100; Abcam) were detected by Alexa fluor 488 or Alexa fluor 594 (Invitrogen) conjugated secondary antibodies. piPSC images were obtained by sequential scanning of the sample using the LSM 510 Meta NLO microscope (Zeiss, Jena, Germany) and merged with the Zeiss LSM image browser (ver. 3.2.0.70).

\section{Cell viability and cell cycle analysis}

Viability and apoptosis of cells was quantified by using the Annexin V Alexa Fluor 488 \& PI Dead Cell Apoptosis kit (Invitrogen) according to the manufacturer's protocol. For the cell cycle analysis, Cells were fixed by adding cold ethanol (70\%) for $15 \mathrm{~min}$ and centrifuged at 1,200 rpm for 4 min. Fixed cells were resuspended in PBS containing 10 $\mathrm{mg} / \mathrm{mL}$ RNase $\mathrm{A}$ and incubated at $37^{\circ} \mathrm{C}$ for $1 \mathrm{~h}$, and then, cells were stained by $1 \mathrm{mg} / \mathrm{mL}$ propidium iodide (PI). The cell cycle was analyzed using PI DNA staining and a flow cytometer equipped with the BD CellQuest Pro Software (BD Bioscience, USA). All experiments were performed on at least 3 independent cell samples.

\section{Reverse transcription and quantitative PCR}

RNA was extracted using the DNA RNeasy plus mini kits (Qiagen) following the manufacturer's protocol. $\mathrm{m}$ RNA was reverse transcribed using the SuperScript ${ }^{\circledR}$ VI-

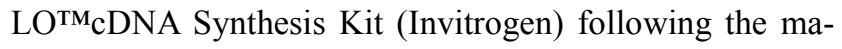
nufacturer's protocol. Quantitative PCR was performed using the Power SYBR ${ }^{\circledR}$ Green PCR Master Mix (Applied Biosystems) on the 7,500 Fast Real-Time PCR System (Applied Biosystems) with Oct4 (forward; 5'-AGTCCCAGGACATCAAAGCG-3', reverse; 5'-AGCTGCAAAGCCTCAAAACG-3') and gapdh (forward: 5'-GGGCGTGAACCATGAGAAGT-3', reverse: 5'-GTCATGAGTCCCT-
CCACGAT-3'). The conditions for real-time RT-PCR were as follows: $95^{\circ} \mathrm{C}, 5 \mathrm{~min}$, followed by 35 amplification cycles $\left(95^{\circ} \mathrm{C}, 5 \mathrm{sec} ; 60^{\circ} \mathrm{C}, 10 \mathrm{sec}\right)$. The reaction was terminated by an elongation and a data acquisition step at $72{ }^{\circ} \mathrm{C}$ for $30 \mathrm{sec}$.

\section{Statistical analysis}

All data were analyzed with Duncan's multiple range tests, using the general linear model procedure with SAS software (SAS Institute, Inc., Cary, NC, USA) and at least three replicates were performed for each experiment. A probability of $P<0.05$ was considered significantly significant.

\section{RESULTS}

PEFs were reprogrammed by transduction with six human factors (OCT4, KLF4, NANOG, SOX2, C-MYC, and LIN28). The established colonies showed typical ESC morphology which are resembled with mouse ESCs (Fig. 1A) and they were positive for AP (Fig. 1B and C). Furthermore, immunostaining showed that they expressed pluripotent markers, OCT4 and NANOG (Fig. 1D-G). piPSCs were able to form EBs and they expressed all markers for the three germ layers, ectoderm (Nestin and Otx), endoderm (Sox17 and Gata6) and mesoderm (Eomes and $T$ (brachyary)) (Fig. 2). piPSCs could passage on both feeder systems and Matrigel coated plates with stem cell medium every three to four days. The several chemicals related with cell cycle arrest were investigated for the synchronization of piPSCs at G1 phase.

As shown in Table 1, piPSC treated with $100 \mu \mathrm{M}$ DAI for $12 \mathrm{~h}$ were effectively arrested at G1 phase, which is significantly higher than among others $(P<0.05)$, and OLO group showed significantly higher proportion of cell in the G2/M phase then non-treated control $(P<0.05)$. 


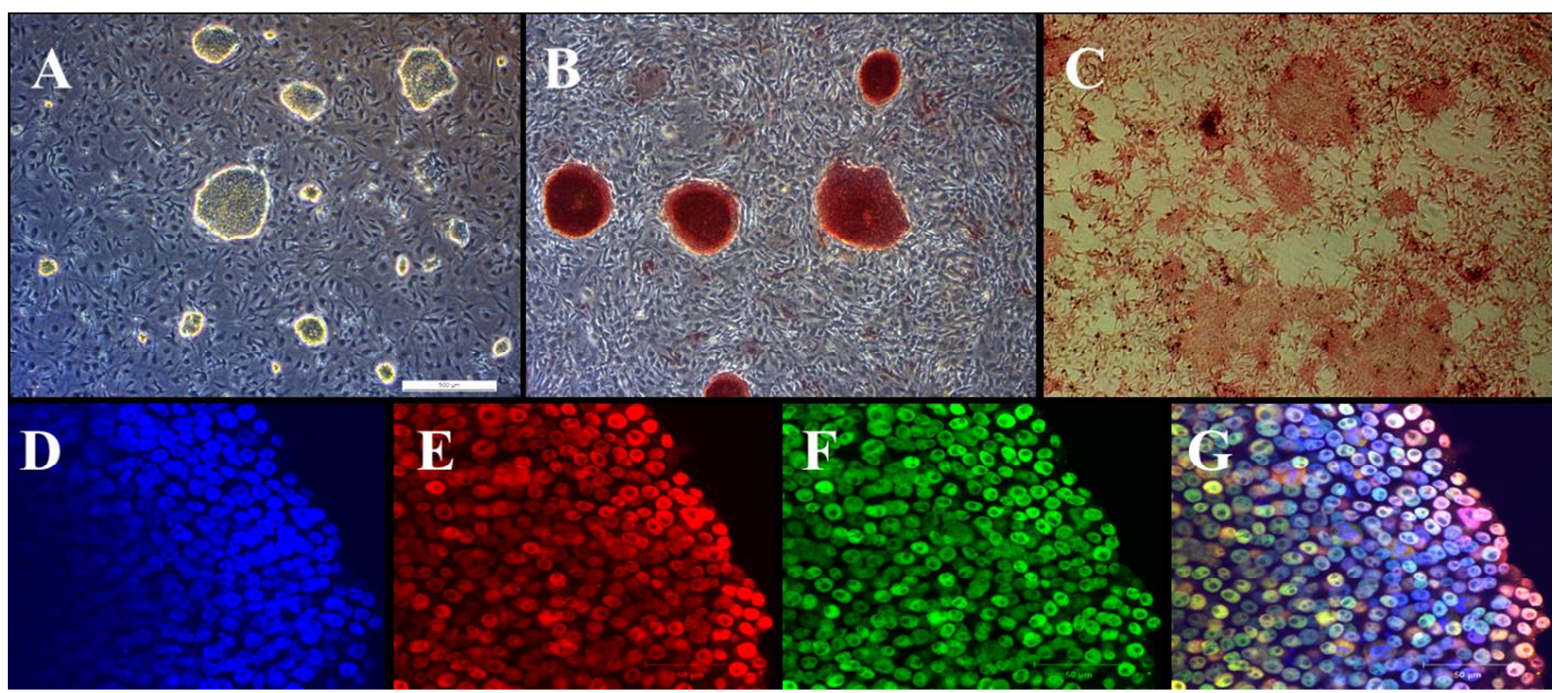

Fig. 1. Morphologies and pluripotent gene expression of porcine induced pluripotent stem cells. Colonies show similar morphology to mouse ESCs (A) and they are positive for alkaline phosphatase (AP) in both feeder (B) and feeder-free (C) culture conditions. Pluripotency markers, OCT4 (E) and NANOG (F) were highly expression in piPSC colony. D; DNA, G; merged image. Scale bars indicate $500 \mu \mathrm{m}$ in A-C and $50 \mu \mathrm{m}$ in D-G, respectively.

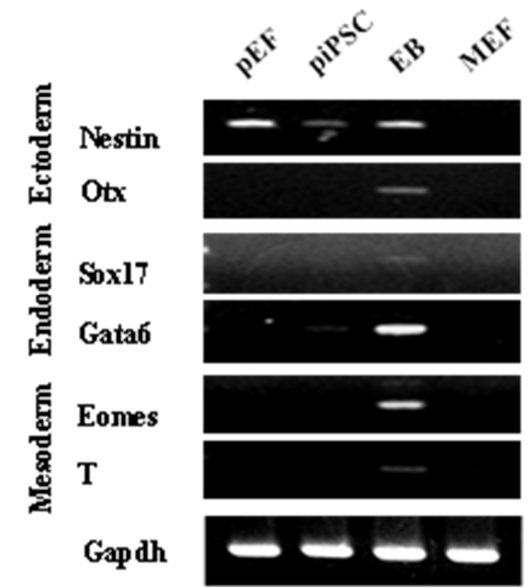

Fig. 2. In vitro differentiation of porcine iPSCs. Embryoid bodies were cultured in stem cell media without LIF for 10 days. RT-PCR analysis shows that all differentiation makers (Ectoderm, Nestin and Otx; Endoderm, Sox 17 and Gata6; Mesoderm, Eomes and $T$ (brachyary)) for the three germ layers were expressed in the EBs.

Viability was decreased by treatment of STA and ROSC, whereas there are no differences among non-treated control, DAI and OLO groups (Fig. 3A). Assessment with the apoptotic assay in piPSCs treated with the chemicals tested here, showed that apoptosis was induced by STA (15.0 $\% \pm 1.33)$ and $\operatorname{ROSC}(15.3 \% \pm 1.45)$, whereas, non-treated control $(5.3 \% \pm 1.33)$, DAI $(6.0 \% \pm 0.57)$ and OLO $(8.3 \%$ \pm 1.45 ) did not induce apoptosis (Fig. 3B).

To confirm whether the pluripotent gene, OCT4, was changed in piPSCs after treatment of cell cycle regulators, real time quantitative PCR was performed. As shown in Fig. 4, significant decrease in the number of OCT4-positive piPSCs was observed in STA $(25.1 \% \pm 0.48)$, ROSC $(43.4 \% \pm 0.65)$ and OLO $(31.9 \% \pm 0.56)$ groups compared to non-treated control $(65.5 \pm 0.63)$, by contrast, DAI $(64.9 \% \pm$ 1.10) did not affected on the expression of OCT4 $(P<0.05)$.

\section{DISCUSSION}

Numerus genetically modified pigs have been generated by NT using somatic cell, because they have potential applications in both the livestock industry and biomedical research (Dai et al., 2002; Lai et al., 2002; Kolber-Simonds et al., 2004; Prather et al., 2004). As mentioned above pluripotent stem cells may be ono of good sources for creating 
Table 1. Effects of chemical treatments on the cell cycle distribution of porcine induced pluripotent stem cells

\begin{tabular}{lccc}
\hline & $\mathrm{G} 0 / \mathrm{G} 1$ & $\mathrm{~S}$ & $\mathrm{G} 2 / \mathrm{M}$ \\
\hline Control & $37.5 \pm 0.2^{\mathrm{b}}$ & $34.0 \pm 0.6^{\mathrm{a}}$ & $28.5 \pm 0.4^{\mathrm{b}}$ \\
Staurosporine $(20 \mathrm{nM})$ & $35.9 \pm 0.9^{\mathrm{b}}$ & $35.2 \pm 0.6^{\mathrm{a}}$ & $28.8 \pm 1.0^{\mathrm{ab}}$ \\
Daidzein $(100 \mu \mathrm{M})$ & $41.9 \pm 0.9^{\mathrm{a}}$ & $26.1 \pm 0.9^{\mathrm{b}}$ & $32.0 \pm 2.3^{\mathrm{ab}}$ \\
Roscovitine $(10 \mu \mathrm{M})$ & $32.6 \pm 1.9^{\mathrm{bc}}$ & $33.7 \pm 1.5^{\mathrm{a}}$ & $33.7 \pm 1.8^{\mathrm{ab}}$ \\
Olomoucine $(200 \mu \mathrm{M})$ & $30.3 \pm 1.5^{\mathrm{c}}$ & $33.1 \pm 2.3^{\mathrm{a}}$ & $36.6 \pm 4.4^{\mathrm{a}}$
\end{tabular}

Mean values \pm SD of the cell percentage in each cell cycle compartment measured in at least three independent experiments are reported.

${ }^{\mathrm{a}-\mathrm{c}}$ Values with different superscripts are significantly different $(P<0.05)$.

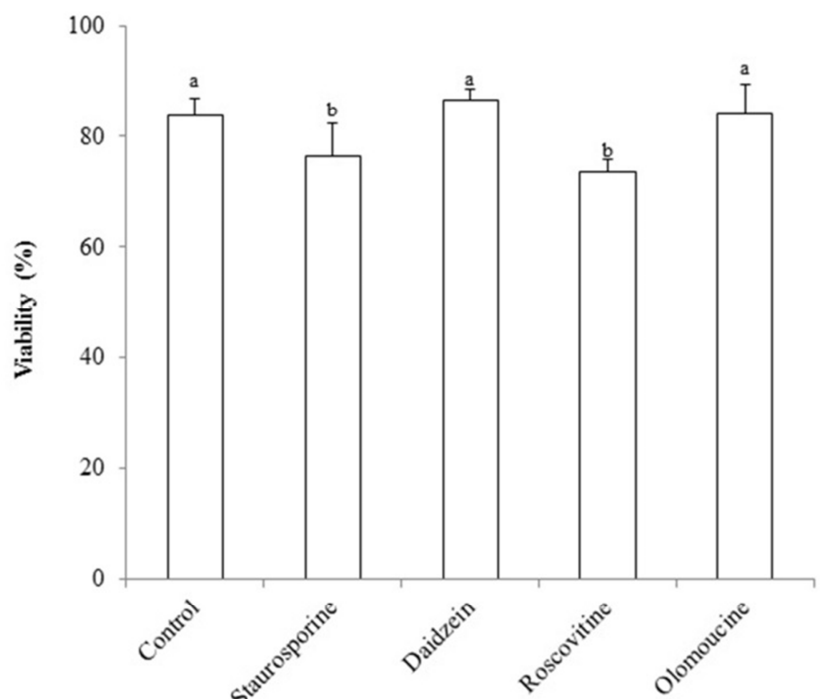

(A)

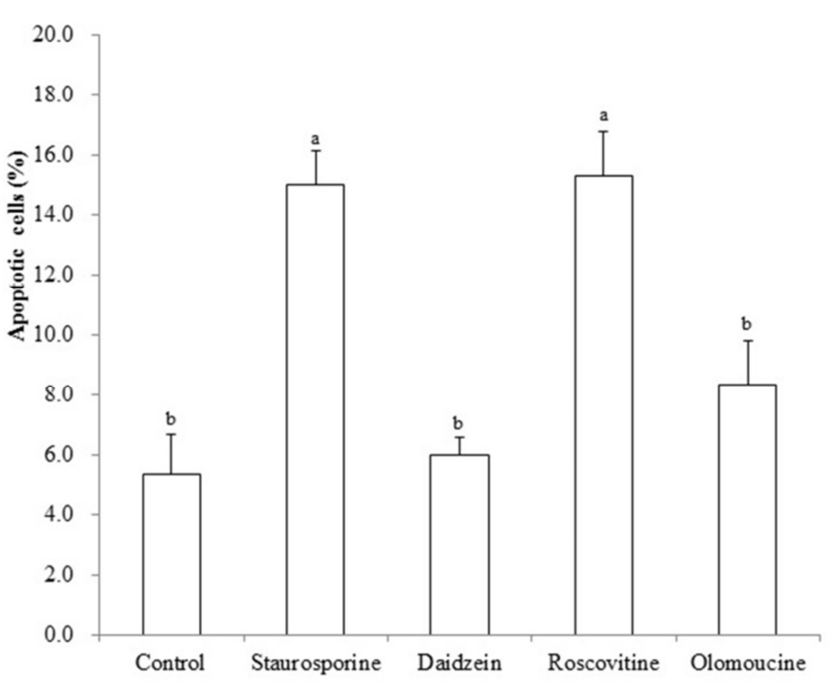

(B)

Fig. 3. Effects of chemical treatments on cell viability $(A)$ and apoptosis $(B)$ of porcine induced pluripotent stem cells. piPSCs were treated with staurosporine (STA, $20 \mathrm{nM}$ ), daidzein (DAI, $100 \mu \mathrm{M})$, roscovitine (ROSC, $10 \mu \mathrm{M})$ or olomoucine (OLO, $200 \mu \mathrm{M}$ ) for $12 \mathrm{~h}$, respectively. Different superscripts (a and b) are significantly different $(P<0.05)$, error bars represent standard error of the mean (SEM).

transgenic animals. Pluripotent cells have a high rate of proliferation by an abbreviated cell cycle, in which G1 phase is also abbreviated. This characteristic may be one of limitations on the usage of piPSCs as a donor for NT. In the present study, piPSCs were generated and investigated for the cell cycle synchronization of them at G1 phase.

piPSCs were generated by transduction with six human factors (OCT4, KLF4, NANOG, SOX2, C-MYC, and LIN28) and they showed typical ESC characteristics. Furthermore, they could passage on both feeder systems and matrigel coated plates with stem cell medium as previously reported one (Kwon et al., 2013). Although, proportion of Oct-4 negative cells was increased when they were continuously passaged onto a matrigel coated plate (without 


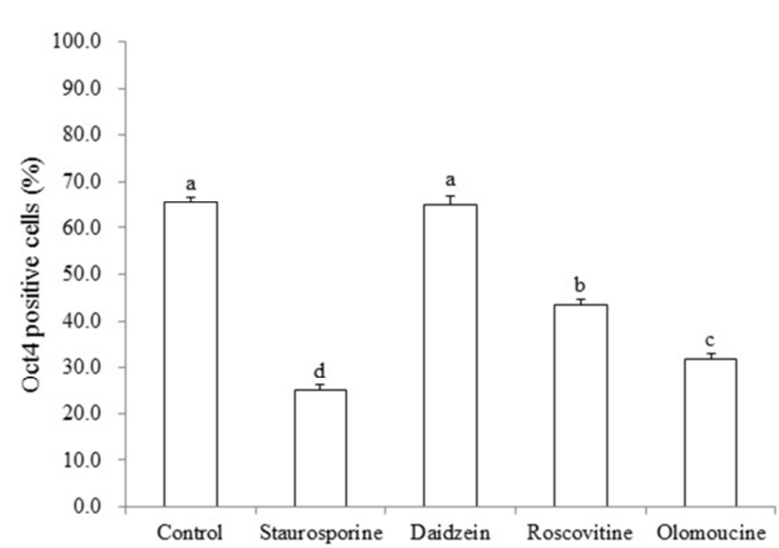

Fig. 4. Effects of chemical treatments on Oct4 expression of porcine induced pluripotent stem cells. piPSCs were treated with staurosporine (STA, 20 $\mathrm{nM}$ ), daidzein (DAI, $100 \mu \mathrm{M}$ ), roscovitine (ROSC, $10 \mu \mathrm{M})$ or olomoucine $(\mathrm{OLO}, 200 \mu \mathrm{M})$ for $12 \mathrm{~h}$, respectively. Different superscripts (a-d) are significantly different $(P<0.05)$, error bars represent standard error of the mean (SEM).

MEF), we used feeder free system to facilitate the analysis of cell cycle experiment.

The several chemicals related with cell cycle arrest were investigated for the synchronization of piPSCs at G1 phase. G1 phase progression and G1/S phase transition are regulated by CDK2 and CDK4. In this point, DAI could decrease in the expression of cyclin D, CDK2, and CDK4. It was reported that DAI caused cell cycle arrest at the G1 and $\mathrm{G} 2 / \mathrm{M}$ phases in human breast cancer cells (Wang et al., 2002; Choi and Kim, 2008), but it could induce apoptosis directly without altering the cell cycle distribution $(\mathrm{Su}$ et al., 2000). In agree with these results, piPSC were effectively arrested at G1 phase, when they were treated with $100 \mu \mathrm{M}$ DAI for $12 \mathrm{~h}$. Furthermore, DAI did not affect the viability, apoptosis and Oct4 expression of piPSCs. These results indicate that DAI is one of candidates for cell cycle synchronization of $\mathrm{p}$ iPSCs.

Both OLO and ROSC are also a cyclin-dependent kinase (CDK) inhibitor which can regulate the activity of cyclin $\mathrm{A}, \mathrm{B}$ and $\mathrm{E}$ kinases resulting in arrest cells in $\mathrm{G} 1 / \mathrm{S}$ and G2/M phase (Meijer, 1996; Alessi et al., 1998). In con- trast, STA is known as a non-specific inhibitor of PKC and of CDK1 which is capable of blocking cell cycle progression at $\mathrm{G}$, in non-transformed cells but not in transformed cells (Crissman et al., 1991). Although low STA concentrations (10-20 nM) arrest normal cells in early G1 phase, a dominant $\mathrm{G} 2$ arrest can be occurred at a high concentration (Crissman et al., 1991; Gadbois et al., 1992; Alessi et al., 1998). In case of goat fibroblast experiment, OLO could effectively arrest cells at G1 phase, and the efficiency of cell cycle inhibition could be increased when it was used in combination with serum starvation (Yu et al., 2003). Previous reports showed that a predominant arrest at G1 phase in normal human fibroblasts could be induced by a 10-fold lower concentration of ROSC treatment than that of OLO (Meijer, 1996; Alessi et al., 1998). Unlike these results, ROSC, OLO and STA have no effects on cell cycle inhibition in piPSCs, whilst ROSC induced a reduction of cell viability and an increased apoptosis in piPSCs. In addition, these chemicals affected on Oct4 expression in piPSCs which may be due to differences of chemical accessibility between in somatic cells and piPSCs.

The goal of the present study was to find the appropriate agent for synchronizing the piPSCs at G1 phase in cell cycle. Thus, pre-implantation development of a reconstructed embryo may influenced by the epigenetic status of the donor nucleus. If piPSCs could be synchronized at G1 phase efficiently, they might be the best source as a nuclear donor for NT, because pluripotent cells have more erased epigenetic status than somatic cells which may facilitate the transferred nuclear into oocyte to be reprogrammed safely. Our results suggest that DAI could be used for synchronizing piPSCs at G1 stage and has any deleterious effect on survival and pluripotency sustaining of piPSCs.

\section{ACKNOWLEDGMENTS}

This work was carried out with the support of "Cooperative Research Program for Animal Science \& Technology 
Development (Project No. PJ01095601)" of National Institute of Animal Science, Rural Development Administration, Republic of Korea.

\section{CONFLICT OF INTERESTS}

The authors declare that there is no financial conflict of interests to publish these results.

\section{REFERENCES}

Alessi F, Quarta S, Savio M, Riva F, Rossi L, Stivala LA, Scovassi AI, Meijer L, Prosperi E (1998) The cyclin-dependent kinase inhibitors olomoucine and roscovitine arrest human fibroblasts in G1 phase by specific inhibition of CDK2 kinase activity. Exp Cell Res 245:8-18.

Becker KA, Ghule PN, Therrien JA, Lian JB, Stein JL, Van Wijnen AJ, Stein GS (2006) Self-renewal of human embryonic stem cells is supported by a shortened G1 cell cycle phase. J Cell Physiol 209: 883-893.

Campbell K, Loi P, Otaegui PJ, Wilmut I (1996) Cell cycle co-ordination in embryo cloning by nuclear transfer. Rev Reprod 1:40-46.

Choi EJ, Kim GH (2008) Daidzein causes cell cycle arrest at the G1 and G2/M phases in human breast cancer MCF-7 and MDA-MB-453 cells. Phytomedicine 15:683-690.

Crissman HA, Gadbois DM, Tobey RA, Bradbury EM (1991) Transformed mammalian cells are deficient in kinase-mediated control of progression through the G1 phase of the cell cycle. Proc Natl Acad Sci USA 88:7580-7584.

Dai Y, Vaught TD, Boone J, Chen S-H, Phelps CJ, Ball S, Monahan JA, Jobst PM, McCreath KJ, Lamborn AE (2002) Targeted disruption of the $\alpha 1,3$-ga- lactosyltransferase gene in cloned pigs. Nat Biotechnol 20:251-255.

Fan N, Chen J, Shang Z, Dou H, Ji G, Zou Q, Wu L, He L, Wang F, Liu K, Liu N, Han J, Zhou Q, Pan D, Yang D, Zhao B, Ouyang Z, Liu Z, Zhao Y, Lin L, Zhong C, Wang Q, Wang S, Xu Y, Luan J, Liang Y, Yang Z, Li J, Lu C, Vajta G, Li Z, Ouyang H, Wang H, Wang Y, Yang Y, Liu Z, Wei H, Luan Z, Esteban MA, Deng H, Yang H, Pei D, Li N, Pei G, Liu L, Du Y, Xiao L, Lai L (2013) Piglets cloned from induced pluripotent stem cells. Cell Res 23:162-166.

Gadbois DM, Crissman HA, Tobey RA, Bradbury EM (1992) Multiple kinase arrest points in the G1 phase of nontransformed mammalian cells are absent in transformed cells. Proc Natl Acad Sci USA 89:86268630.

Ghule PN, Medina R, Lengner CJ, Mandeville M, Qiao M, Dominski Z, Lian JB, Stein JL, van Wijnen AJ, Stein GS (2011) Reprogramming the pluripotent cell cycle: restoration of an abbreviated G1 phase in human induced pluripotent stem (iPS) cells. J Cell Physiol 226:1149-1156.

Hanna J, Cheng AW, Saha K, Kim J, Lengner CJ, Soldner F, Cassady JP, Muffat J, Carey BW, Jaenisch R (2010) Human embryonic stem cells with biological and epigenetic characteristics similar to those of mouse ESCs. Proc Natl Acad Sci USA 107:9222-9227.

Hochedlinger K, Jaenisch R (2006) Nuclear reprogramming and pluripotency. Nature 441:1061-1067.

Hwang S, Oh KB, Kwon DJ, Ock SA, Lee JW, Im GS, Lee SS, Lee K, Park JK (2013) Improvement of cloning efficiency in minipigs using post-thawed donor cells treated with roscovitine. Mol Biotechnol 55:212-216.

Kim JM, Ogura A, Nagata M, Aoki F (2002) Analysis of the mechanism for chromatin remodeling in em- 
bryos reconstructed by somatic nuclear transfer. Biol Reprod 67:760-766.

Kolber-Simonds D, Lai L, Watt SR, Denaro M, Arn S, Augenstein ML, Betthauser J, Carter DB, Greenstein JL, Hao Y, Im GS, Liu Z, Mell GD, Murphy CN, Park KW, Rieke A, Ryan DJ, Sachs DH, Forsberg EJ, Prather RS, Hawley RJ (2004) Production of alpha-1,3-galactosyltransferase null pigs by means of nuclear transfer with fibroblasts bearing loss of heterozygosity mutations. Proc Natl Acad Sci USA 101:7335-7340.

Kwon D, Jeon H, Oh K, Ock S, Im G, Lee S, Im S, Lee J, Oh S, Park J, Hwang S (2013) Generation of leukemia inhibitory factor-dependent induced pluripotent stem cells from the massachusetts general hospital miniature pig. Biomed Res Intl doi:10. $1155 / 2013 / 140639$.

Kwon DJ, Park CK, Yang BK, Cheong HT (2008) Control of nuclear remodelling and subsequent in vitro development and methylation status of porcine nuclear transfer embryos. Reproduction 135:649-656.

Lai L, Kolber-Simonds D, Park KW, Cheong HT, Greenstein JL, Im GS, Samuel M, Bonk A, Rieke A, Day BN, Murphy CN, Carter DB, Hawley RJ, Prather RS (2002) Production of alpha-1,3-galac- tosyltransferase knockout pigs by nuclear transfer cloning. Science 295:1089-1092.

Meijer L (1996) Chemical inhibitors of cyclin-dependent kinases. Trends Cell Biol 6:393-397.

Prather RS, Sutovsky P, Green JA (2004) Nuclear remodeling and reprogramming in transgenic pig production. Exp Biol Med 229:1120-1126.

Su SJ, Yeh TM, Lei HY, Chow NH (2000) The potential of soybean foods as a chemoprevention approach for human urinary tract cancer. Clin Cancer Res 6:230236.

Wang HZ, Zhang Y, Xie LP, Yu XY, Zhang RQ (2002) Effects of genistein and daidzein on the cell growth, cell cycle, and differentiation of human and murine melanoma cells. J Nutr Biochem 13:421-426.

Yu Y, Sun X, Jiang H, Han Y, Zhao C, Tan J (2003) Studies of the cell cycle of in vitro cultured skin fibroblasts in goats: work in progress. Theriogeno$\operatorname{logy} 59: 1277-1289$.

Yuan Y, Lee K, Park KW, Spate LD, Prather RS, Wells KD, Roberts RM (2014) Cell cycle synchronization of leukemia inhibitory factor (LIF)-dependent porcine-induced pluripotent stem cells and the generation of cloned embryos. Cell Cycle 13:1265-1276. 